\title{
A STOCK INDEX MUTUAL FUND WITHOUT NET CAPITAL GAINS REALIZATIONS
}

Joel M. Dickson

John B. Shoven

Working Paper No. 4717

\author{
NATIONAL BUREAU OF ECONOMIC RESEARCH \\ 1050 Massachusetts Avenue \\ Cambridge, MA 02138 \\ April 1994
}

We would like to thank Jeremy Bulow, John Andrew McQuown, Charles Schwab, and seminar participants at Boston University, Northwestern, Penn State, Stanford, the Federal Reserve Board of Governors, and the NBER's Public Economics Meetings for helpful comments and discussions. We would also like to thank George Sauter at The Vanguard Group for providing us with key data and insight into the management of Vanguard's Index 500 Fund. Financial support was provided by Charles Schwab \& Company. The research presented, the opinions expressed, and any remaining errors are solely those of the authors. This paper is part of NBER's research program in Public Economics. 
NBER Working Paper \#4717

April 1994

\title{
A STOCK INDEX MUTUAL FUND WITHOUT NET CAPITAL GAINS REALIZATIONS
}

\begin{abstract}
This paper reconsiders the literature on tax options by examining the ability to defer net capital gains realizations within an equity portfolio whose constituents change over time. Unlike previous studies on the value of tax options, this paper examines after-tax returns to shareholders within an equity mutual fund. The mutual fund context allows certain features of the United States' tax laws -- namely, wash-sale rules and the offsetting of short-term and long-term capital gains and losses -- to be incorporated in assessing the potential improvement in post-tax returns to investors engaging in tax minimization strategies.

Specifically, this paper examines the feasibility of managing open-end and closed-end Standard and Poor's 500 index funds which defer net capital gains realizations. A combination of HIFO (highest in, first out) accounting procedures and the systematic booking of significant losses in portfolio constituents would have allowed the open-end fund variant to match the annual pre-tax return of Vanguard's Index 500 Fund while improving annual after-tax performance by as much as ninety-seven basis points through the elimination of all capital gains realizations between 1977 and 1991. Deferring capital gains is shown to be easier for open-end funds relative to closed-end funds while the additional turnover required to implement these strategies is quite modest. The authors name the tax-sensitive funds in this paper "SURGE (Strategies Using Realized Gains Elimination) funds."
\end{abstract}

Joel M. Dickson

Department of Economics

Stanford University

Stanford, CA 94305
John B. Shoven

Department of Economics

Stanford University

Stanford, CA 94305

and NBER 


\section{A Stock Index Mutual Fund Without Net Capital Gains Realizations}

Mutual fund prospectuses provide a great deal of information about the operation, style, investment philosophy, and past performance of funds. These disclosures, most required by the Securities and Exchange Commission, are meant to provide prospective investors with the necessary information to compare mutual funds in order to make informed financial allocation decisions. One principal drawback of the current disclosure laws, however, is that all performance data are reported as pre-tax values even though many shareholders are subject to federal, state, and local taxation on the dividend and realized capital gains distributions made by different funds.

Many popular sources of investment analysis and advice, such as financial newspapers and magazines, use the pre-tax measures to rank the past performance of mutual funds. Dickson and Shoven (1993), however, find that tax management policies across equity mutual funds differ widely, causing the post-tax rankings to deviate significantly from their pre-tax counterparts. Even if past before-tax performance may not be indicative of future before-tax performance, the after-tax calculations allow investors to identify better those funds which systematically manage their portfolios to minimize their shareholders' current tax liability by taking advantage of the ability to defer taxation until capital gains are realized.

Some mutual funds recognize the importance of maximizing after-tax returns for their investors. The prospectus of the Schwab 1000 Fund, for example, states that "the Fund's investment policies are designed to minimize current capital gains tax liability" (p. 4). Furthermore, Dickson and Shoven (1993) show that if an index fund, such as Vanguard's Index 
500 Fund which replicates Standard and Poor's 500 Stock Index (S\&P 500), could manage its portfolio to eliminate all capital gains distributions to its shareholders, after-tax performance would have been greatly enhanced.

In this paper, we consider the feasibility of creating and implementing a tax-conscious "index" fund which eliminates all realized capital gains distributions for long horizons. The accounting and trading strategies used to minimize realized capital gains taxes in our stock portfolio are motivated with the theoretic research on capital gains tax minimization by Constantinides (1983) and Stiglitz (1983). Our specific aim is to replicate the S\&P 500 index from August, 1976, when Vanguard's Index 500 Fund commenced, through December, 1991. We name our constructed fund a SURGE fund (Strategies Using Realized Gains Elimination) and consider both closed-end and open-end SURGE variants.

The analysis in this paper provides a number of interesting additions to the literature on the value of tax options. Constantinides (1984) and Dammon, Dunn, and Spatt (1989) consider trading strategies on individual stocks which have survived for some specified time period. By focusing on the S\&P 500, we can analyze the benefits of tax-motivated trading within a portfolio of stocks whose constituents are changing over time (i.e., forced realizations) and where only net capital gains on the entire portfolio are considered. In addition, simulations of closed-end and open-end S\&P 500 mutual funds allow insight about the advantages of competing investment company structures to engage in tax-minimization strategies.

A number of additional questions must also be addressed. First, is the fund we create able to track the S\&P 500 successfully? That is, are we able to match the annual pre-tax return while improving after-tax performance relative to a mutual fund which completely replicates the index? 
Second, will the trading strategies we examine eliminate realized capital gains distributions over long periods of time even as the proportion of unrealized gains in our portfolio grows? Finally, offsetting realized gains with realized losses implies that, relative to a true index fund, a SURGE fund's turnover rate will be higher. Do the costs associated with the increased turnover outweigh the benefits of eliminating gains distributions? In other words, are the transaction costs associated with SURGE funds prohibitively high?

The paper proceeds as follows. Section I details the methodology of implementing our SURGE fund. Section II describes the data we used to create our variant of an S\&P 500 index fund. Section III presents the results of our analysis and focuses on the ability of SURGE funds to enhance after-tax performance for shareholders and also discusses differences between closedend and open-end funds which exhibit exactly the same investment strategies and management. Section IV concludes and summarizes.

\section{Methodology}

We choose to create our so-called SURGE fund based on the S\&P 500 index for two main reasons. First, the S\&P 500 is constantly used as the benchmark against which equity mutual funds are measured. Second, it would be relatively simple to construct a stock portfolio, expost, which is able to offset realized gains with realized losses for long horizons. Confining ourselves to the S\&P 500 firms, however, facilitates straightforward pre-tax comparisons with the benchmark while restricting our available trading strategies.

The strategies examined in our simulations below rely on the ability of an investment 
manager to minimize net capital gains realizations for his/her shareholders. One relevant institutional feature regarding regulated investment companies (RICs) must be emphasized'. Unlike individual shareholders who, under current tax laws, may deduct net capital losses totalling up to $\$ 3000$ per year from ordinary income, RICs cannot distribute net capital losses to their shareholders. In addition, individual investors may carryforward capital losses indefinitely to offset future capital gains realizations while RICs may carryforward net realized losses for eight years following the loss year. RICs distribute both short-term and long-term capital gains, if necessary, but any losses offset either short-term or long-term realized capital gains dollar for dollar.

The general construction of these SURGE funds allows for the accounting practice of specific identification in the sale of securities. Dividends and other income received from distributions, left-over cash from additions and deletions from the index, and, in the case of open-end SURGE variants, net sales data are combined with the current portfolio at the end of each month. Anytime a particular security is purchased, we record the number of shares bought, the purchase date, and the price paid per share. We have, therefore, many different stock "slices" with many different bases for a given security in our portfolio.

1 Technically, a "mutual" fund is an open-end regulated investment company. Closed-end funds are not "mutual" funds. We will, however, tend to use regulated investment company and mutual fund interchangeably. 
At a given time $t$, the value of our S\&P 500 portfolio can be expressed as

$$
\sum_{i=1}^{500} \sum_{j=1}^{N_{k}} P_{i j} S_{i j}
$$

where $P_{k}$ is security $i$ 's price at time $t, N_{k}$ is the number of "slices" of security $i$ held at $t$, and $S_{i j}$ is the number of shares held in the jth slice of security $i$. The basis of the portfolio at time $t$ may be similarly expressed as

$$
\sum_{i=1}^{500} \sum_{j=1}^{N_{k}} P_{i j} S_{i j}
$$

where $P_{i j}$ is the per-share purchase price of the $j$ th slice of security $i$.

\section{HIFO Accounting Procedure}

There are two strategies we will use to try to eliminate net capital gains realizations. The first strategy is that whenever a portion of a security's holdings must be sold, we always sell the highest basis shares first. If our fund must sell $\mathrm{L}_{\mathfrak{n}}$ shares of security $i$ at time $t$, then, using the notation of equation (1), the fund will sell the slice $S_{i j}$ corresponding to the per-share price: $\max \left\{P_{i j} ; j=1, \ldots, N_{i h}\right\}^{2}$. The HIFO (highest in, first out) strategy is implemented when shares

${ }^{2}$ If $\mathrm{L}_{n}$ is greater than the number of shares contained in slice $S_{i j}$ with the highest per-share basis, then we just continue choosing the highest basis slices until all $\mathrm{L}_{\mathfrak{n}}$ shares are sold. 
must be sold due to re-weightings of the index not resulting solely from share price movements (e.g., share repurchases) or, in the case of our open-end SURGE funds, when a monthly ebb of money must be met by selling some of the current stock holdings ${ }^{3}$. The HIFO accounting procedure does not alter the true portfolio weights in any manner. All that the HIFO approach does is target which tax lot of a security to sell conditional on a sale being required. Huddart and Narayanan (1993) use the HIFO approach in their study of tax motivated trading by institutional investors such as mutual funds.

\section{Realizing Capital Losses}

The second tax advantaged strategy is for our fund to realize capital losses to offset future capital gains liabilities. Booking capital losses mitigates the effects of forced realizations that may result in capital gains income (e.g., cash mergers). Constantinides (1983) shows that in the presence of no transaction costs and a realization tax on capital gain income (with no difference between short-term and long-term gains tax rates), individual investors would optimally realize losses as they accrue while deferring all gains. A simple example illustrates the advantage of this approach. Suppose a security sells for $\$ 10$ at time $0, \$ 5$ at time 1 , and $\$ 10$ at time 2 . If

3 One may also consider implementing a modified HIFO approach where a distinction is made between short-term and long-term capital gains. If every investor in the fund is subject to a thirty-six percent marginal tax rate on short-term capital gains and a twenty-eight percent rate on long-term gains, then investors would prefer up to a $\$ 1.125((1-.28) /(1-.36))$ longterm gain for each $\$ 1$ short-term capital gain. We do not implement this modified HIFO approach since, in all of our simulations, we never a distribute a net short-term gain and, in most simulations; we never distribute a net capital gain (i.e., we carryforward losses which would be used up faster under this modified HIFO procedure). 
an investor would have sold and repurchased the security at time 1 (without transaction costs), she would have a $\$ 5$ loss to offset either the gain from time 1 to time 2 (if the security is sold at time 2) or gains in other parts of her portfolio. A buy and hold strategy in this case would obviously be inferior: the value of the portfolio is the same but there is no option available to offset gains in the rest of the investor's portfolio in the event of a forced liquidation.

Another example is provided by Figure 1 which shows that redundant securities on a pre-tax basis can imply very different post-tax results for an investor's portfolio. As depicted in Figure 1 , consider a $\$ 1$ investment in a security which appreciates $10 \%$ in one state of the world (occurring with probability p) and appreciates $5 \%$ in all other states of the world (with probability 1-p). This security can be replicated by a $\$ 0.50$ investment in a security which appreciates $30 \%$ in one state of the world and depreciates $10 \%$ in all other states and another $\$ 0.50$ investment in a security which depreciates $10 \%$ in the first state and appreciates $20 \%$ in all other states. While the pre-tax returns are identical, an opportunity to realize a capital loss to offset capital gains in the investor's portfolio does not exist with the first security since it appreciates in value in all states of the world. One of the replicating securities, however, is guaranteed to depreciate in value over each period and, therefore, an investment made at the beginning of the period could be sold at a capital loss (in the absence of transaction costs) and used to offset gains in other parts of the portfolio. Figure 1 demonstrates Constantinides' (1983) point that higher variance securities have larger tax option values because of the increased likelihood of realizing a loss position. 


\section{Wash-Sale Restrictions on Realizing Capital Losses}

The biggest impediment in implementing this strategy of realizing losses as they accrue is the wash-sale rule. A wash sale disallows the realization of a capital loss if the security which was sold at a loss had been purchased within the preceding thirty days. The wash sale rule also applies if the security sold at a loss is repurchased within the thirty days following the sell date. If a loss is disallowed, a basis and holding period adjustment is made to another slice of that security's holdings".

Without the wash sale rule, a fund could sell and immediately repurchase a position whose basis is higher than its current market value, thereby booking a capital loss without deviating from the fund's current portfolio weights. One obvious strategy for dealing with wash sales is to purchase a security or combination of securities with similar expected return and risk characteristics to replace the stock which is sold at a loss. This possibility provides one potential justification, even if money managers are unable to "beat the market," for more actively managed funds. An index fund is restricted to investments in the index's constituents. If a security is sold to realize a capital loss, an index fund must remain underweighted in that security (and possibly overweighted in the other securities) relative to the true index weights for

4 An example of the wash-sale rule might provide some insight. Suppose an investor purchases 100 shares of a security on December 1,1993 , at $\$ 30$ per share. Another 100 shares are purchased at $\$ 35$ per share on January 3,1994 . On January 24,1994 , the investor wants to sell the shares purchased January 3 at a current share price of $\$ 32$. The loss of $\$ 3$ per share would be disallowed. The basis of the remaining 100 shares would become $\$ 33$ ( $\$ 30$ plus the $\$ 3$ loss disallowed) with a purchase date of November 10, 1993 (December 1 minus the 21 day holding period that the wash sale lot had been held). 
thirty days before a purchase could be made to re-establish the index weights ${ }^{5}$.

Unlike the individual trading strategies considered in Constantinides $(1983,1984)$ and Dammon, Dunn, and Spatt (1989), the wash sale rule complicates the notion of optimally realizing losses in the cases of closed-end and open-end index equity funds. The strategy of realizing losses for our SURGE funds is subject to a tradeoff between tracking the underlying index (i.e., pre-tax return) and the desire to realize capital losses as they accrue. As an extreme example, consider the case where we have a loss position in at least one slice of every security in our portfolio, and we have a net inflow of cash during the month. If we realize every loss position, we could not buy any of the securities because of the wash sale rule, and the cash inflow and money received from the stock sales would have to remain as cash until the following month ${ }^{6}$. Such a strategy would most likely inhibit pre-tax equity returns to the point where the tax savings could not offset the loss in total return.

We view the decision to sell loss positions and temporarily deviate from the index weights as a function of three variables: the difference between the current share price and the original basis (the trigger), the degree to which we allow underweighting of a given security, and the percentage of our total holdings subject to the loss trigger. In all of the SURGE funds

5 In the construction of our SURGE funds below, we use monthly buys or sales of securities and modify the wash sale rule by disallowing a purchase and sale of a security in the same month. If you sold a stock at the end of the previous month, however, you may purchase that security at the end of the current month. In most cases our wash sale period will be 30 or 31 days except for February where our wash sale period will generally be 28 days.

6. A mutual fund would not be restricted from selling shares entirely. A fund can "sell through" the wash sale and account for that portion of the sale subject to the wash sale provisions in a manner similar to the example presented in footnote 4. In our replications, however, we do not "sell through" any wash sales. 
considered in this paper, the trigger for a loss sale is a current share price which is no more than 75 percent of the basis, and, we must be able to sell at least five percent of our total holdings in the security at or below the 75 percent trigger. The five percent minimum is chosen to represent the level at which realizing losses offsets the monthly deviation from the true index weights. We furthermore require that we are never underweighted in any single security by more than 50 percent relative to the true index weights. We refer to this strategy as the 5-50-75 trading rule ${ }^{7}$. If a sale of securities would meet all three of these conditions, then we realize the loss at the end of the current month and do not re-establish the market weights until the end of the following month ${ }^{8}$.

\section{Data}

There are a number of data sources that must be compiled in order to create a S\&P 500 indexed mutual fund. We first obtained a database of all the constituents of the S\&P 500 from Standard and Poor's (S\&P). This database includes the day of a firm's insertion and deletion (if applicable) in the S\&P 500 from the inception of the index in March, 1957. Using S\&P's

7 These numbers are chosen somewhat arbitrarily, and we make no claim that this is an "optimal" strategy. An optimal strategy would depend on the shareholders' preferences with respect to the overweighting and underweighting of securities in the index. Results presented below are robust to deviations in the trigger values and share holding restrictions.

- This strategy of realizing losses is similar to strategy 1 in Constantinides (1984). We do not consider the other trading strategies in Constantinides (1984) and Dammon, et.al. (1989) since these involve a restarting option where a long-term gain is realized to re-establish a shortterm position. Since we never end a year with a net short-term capital gain in any of our replications and RICs cannot distribute capital losses, the restarting option will, most likely, provide no additional benefit to after-tax returns in our SURGE funds. 
list, we pulled stock market return data for each S\&P 500 firm from the Center for Research in Security Prices (CRSP) daily stock price database.

For each firm in the index between July 31, 1976, and December 31, 1991, (the last day of CRSP data available to us) we use CRSP to obtain all price, shares outstanding, and distribution data. CRSP codes all distributions to shareholders of a particular security by type (e.g., dividend, merger, split) and tax status (e.g., taxable as ordinary income, non-taxable, retum of capital). Non-taxable mergers and spin-offs might be taxable for our purposes since the stock received may not be a security in the S\&P 500 index. All non-taxable distributions of stock as coded in CRSP are verified in Capital Changes Reporter published by Commerce Clearing House. When the securities received are not contained in the 500 index, the per-share dollar amount of the distribution is treated as a sale of stock subject to capital gains or losses.

Table 1 shows how deletions have affected the S\&P 500 index for the period from August 1, 1976, to December 31, 1991. For each calendar year, the table reports the total number of deletions and the sum of the percentages of the S\&P 500 that these firms totalled at the time of exit from the S\&P 500. There are a total of 317 deletions (and additions) to the S\&P 500 over our sample period for a combined total of 817 firms in the S\&P 500 index over this time horizon. The merger and take-over rage of the mid and late 1980s is apparent in Table 1. A total of 89 firms, accounting for approximately one-eighth of the index's market capitalization, were deleted from the index in the 1984-1986 period.

There are a number of differences between the dates that a firm is included in the S\&P 500 as provided by Standard and Poor's and the dates that a firm has CRSP data available. Almost all of the discrepancies concem delisting dates. The committee that makes decisions about 
additions and deletions to the S\&P 500 meets only on an occasional basis." If a firm were to delist because of merger or bankruptcy, CRSP data would be available through the security's last trading day. On the other hand, the S\&P 500 committee might not replace the delisted security in the index for a week or more depending on the scheduling of the next committee meeting. While the S\&P 500 always consists of 500 firms, therefore, our constructed index may contain, at times, slightly fewer firms?.

In order to replicate an open-end S\&P 500 index fund, we need some representative net sales data. We obtained from The Vanguard Group actual monthly net sales for the Vanguard Index 500 Fund since its inception in August, 1976. The frequency of the net sales data determines how often we buy and sell shares for our SURGE fund's portfolio. Except for additions and deletions which occur on specific days within a given month, we make purchases or sales of stock based on Vanguard's monthly net sales at the end of each month.

\section{Results}

We consider two types of closed-end and open-end SURGE funds. The first type, "HIFO only," maintains the S\&P 500 market capitalization weights at all times. The "HIFO only" strategy simply sells the highest basis shares when the fund is forced to sell some of the portfolio's holdings. The second type of SURGE fund, "HIFO, 75\%," also follows the HIFO

9 Another difference is the treatment of the AT\&T divesture. The S\&P 500 added the seven baby bells on November 30,1983 . CRSP data for the baby bells, however, do not begin until February 16, 1984. The CRSP data for AT\&T between these dates implicitly contain the returns for the baby bells even though our replicated index fund will explicitly contain only 493 firms over this period. 
strategy with respect to portfolio sales. The "HIFO, $75 \%$ " strategy, in addition, searches through the portfolio at the end of every month for bundles of securities which may be sold to realize capital losses. As described in the methodology section above, a loss is realized if the bundle meets the trading rule where at least 5 percent of a stock's holdings, subject to being underweighted by a maximum of 50 percent, can be sold at a current price not greater than 75 percent of the cost basis. The SURGE "HIFO, $75 \%$ " fund will deviate from the market weights for the month in which a loss is realized in order to satisfy the wash sale restrictions. The excess cash that would have been used to establish the index weights in the stock which was sold at a loss is distributed across all the securities not subject to the wash sale provisions according to the index weights.

The closed-end SURGE funds participate in an initial public offering on July 31,1976 , in which they offer one million shares at a per-share price of ten dollars. The closed-end SURGE funds are assumed to trade at their net asset values (NAV) at each point in time ${ }^{10}$. The openend SURGE variants also commence operations on July 31, 1976, with initial assets of ten million dollars and a $\$ 10 \mathrm{NAV}$. As an estimate of the expenses that each of our SURGE funds incurs, we subtract the annual expense ratios published by Morningstar for the Vanguard Index 500 Fund. At the end of each calendar year, each SURGE fund distributes an ordinary dividend" and a long-term capital gain dividend to its shareholders. We assume that all

10 There is a large finance literature on the paradox of closed-end investment companies trading at prices not equal to their NAVs (see Lee, et.al. (1990) for a general discussion of closed-end anomalies). Since we have no way to characterize the prices at which our closed-end funds would trade, we assume the share prices always equal the NAVs.

"The ordinary dividend includes any net realized short-term capital gains. 
distributions are re-invested in new fund shares.

All of our funds invest 100 percent of their total assets in the S\&P 500 securities subject to the following exceptions. The funds purchase an integer number of shares of each stock. Any fractional shares are held as cash. Dividends and other distributions received during the month are held as cash until the end of the month when new shares can be purchased. Cash received from the deletion of a security is held until a new security is added to the index. Because of differences in CRSP delisting dates versus the S\&P 500 index deletion dates, we may have to hold a cash position from a deletion for two weeks or more. All cash earns the short-term Treasury Bill rate as found in Ibbotson (1993).

The results for our open-end and closed-end SURGE funds are presented in Tables 2 and 3 , respectively. We present results for the five, ten, and fifteen year periods ending on December 31, 1991. For the open-end SURGE funds, the actual returns for Vanguard's Index 500 are reported for comparison purposes. The tables report the end-of-period value of a one dollar investment made at the beginning of the period in each of the funds, the average annual percentage nominal retum, and, for the open-end variants, the percentile rank of the fund in the 147 open-end, equity mutual funds considered by Dickson and Shoven (1993). Return data are presented on a pre-tax, mid-tax, and high-tax basis. The mid-tax and high-tax returns are calculated for a taxable investor facing income and long-term capital gains marginal tax rates based on three and ten times annual median adjusted gross income, respectively ${ }^{12}$. Tables 2

12 See Dickson and Shoven (1993a) for a more detailed description of these hypothetical mid-tax and high-tax investors. 
and 3 also report the average annual portfolio turnover rates $^{13}$ for each of the variants considered over the relevant time period.

\section{Open-End Fund Results}

The results in Table 2 for our tax-conscious, open-end SURGE funds are quite dramatic. On a pre-tax basis, our SURGE funds and Vanguard's Index 500 Fund match almost exactly. In other words, there seems to be no tracking error. This hypothesis is confirmed by Figure 2 which shows that our SURGE funds offer essentially identical annual pre-tax returns as Vanguard's Index 500 each year. On a post-tax basis, however, our S\&P 500 index funds perform much better than Vanguard's S\&P 500 index fund ${ }^{14}$. The high-tax individual earns an annual return approximately $85-95$ basis points higher than the Vanguard 500 with our SURGE funds over the ten and fifteen year horizons. The mid-tax individual sees annual retum increases on the order of $65-70$ basis points. By improving post-tax returns without altering pretax results, these SURGE funds are appropriate alternative investment vehicles to traditional index funds for all investors regardless of the tax status of the shareholders' investment.

The numbers in parentheses in Tables 2 and 3 represent the corresponding liquidation values at the end of the five, ten, and fifteen year periods. The liquidation value is the amount an

13 The portfolio turnover rate is the smaller of sales and purchases of securities made by the fund divided by the fund's average total assets.

14 The reader should note that Vanguard's Index 500 is already an excellent fund for taxable investors as seen by the substantial increases in the post-tax versus pre-tax rankings for every time horizon. 
investor would have if he would have sold his shares at the end of 1991 and paid taxes on any previously unrealized capital gains. Even on a liquidation basis, the long-term deferral advantage of capital gains taxes is evident. Over the 1977-1991 period, an investor in our openend SURGE HIFO, 75\% fund would have had an after-tax return 54 basis points per year higher than that achieved by Vanguard's Index 500.

While return differences are not as dramatic under the liquidation scenario, the liquidation value represents the worst-case scenario. An investor can always leave a fund with no more than his accrued capital gains being realized. Consider an investor having purchased a fund with a $\$ 10$ net asset value, but the next day the fund distributes a $\$ 5$ realized capital gain. If the investor immediately sells the mutual fund shares (which have fallen to a $\$ 5 \mathrm{NAV}$ because of the distribution), then there is no taxable event since the gain and loss will offset each other. The liquidation value can understate the tax deferral advantage because of the step-up in basis at death or if the mutual fund shares are given as a gift.

One of our most intriguing results is that nearly all of the improvement in the post-tax returns results from the simple HIFO only strategy. In this case, the index weights are always maintained since this fund does not engage in additional trading to offset realized gains by booking losses. Taxable investors in our open-end SURGE funds gain only an additional 5-8 basis points per year by combining the HIFO and 5-50-75 trading strategies relative to the HIFO only approach. Investors in more actively managed funds which hold fewer tax lots and turnover their portfolios at greater rates would more likely see more improvement from realizing capital losses since the HIFO only approach works extremely well for an index fund with many tax lots in a relatively fixed universe of securities. 
There are a number of possible explanations for why our HIFO only strategy outperforms Vanguard's Index 500 on an after-tax basis. One possible explanation would be that Vanguard sells shares of those companies participating in non-taxable mergers where the resulting firm is also in the 500 index and purchases the new securities instead of participating directly in the stock swap. We regard this explanation as highly unlikely. Another plausible explanation is that, according to experts within the mutual fund industry, shareholders put a premium on distributions made by a given mutual fund even if it results in additional tax consequences. Mutual funds, therefore, might try to increase realized capital gains distributions to convince shareholders that their investment is performing well. Our conversations with Vanguard, however, indicate that the Index 500 always maintains its passive investment strategy and never tries to increase distribution amounts. This explanation for differences in our results relative to Vanguard's Index 500, therefore, is highly unlikely.

The most obvious explanation would be that Vanguard uses an accounting procedure other than HIFO when it sells securities. This fact has been confirmed in our discussions with Vanguard. The Index 500 uses specific invoicing in the sale of securities but sells the bundle with a cost basis closest to the average cost basis of that security's holdings. Much of the difference between capital gains realizations can be attributed to the HIFO accounting procedure that we use in the construction of our SURGE funds. Another explanation for some of the discrepancies between our simulated funds and Vanguard's Index 500 may be due to the frequency of trading. Because we have access only to monthly cash flow data, we make sales or purchases of securities based on the accumulation of daily net sales figures within a given month. In actuality, Vanguard makes both sales and purchases within a given month in response 
to daily cash flows. This point is discussed in more detail below.

We feel the impressive post-tax performance of our HIFO only approach is also a result of our strategy of meeting monthly ebbs of cash by selling securities ${ }^{15}$. Most equity mutual funds meet net redemptions either by dipping into a small cash reserve (typically $2-5$ percent of total assets) or by using lines-of-credit instead of selling securities. Paying exiting shareholders through cash reserves or very short-term borrowing allows equity funds to maintain their existing portfolios. Our HIFO only strategy, however, is consistent with the notion that occasional ebbs actually can be beneficial to the remaining shareholders if the fund is able to sell off some of its unrealized loss positions. The usual argument that net redemptions are harmful because of realized gains liabilities resulting from the sale of securities (see Jeffrey and Amott (1993)) is based on the assumption of calculating gains with respect to the average appreciation of the securities. Such an assumption does not recognize the ability to use specific invoicing in the bundles of securities to be sold.

\section{Open-End v. Closed-End Fund Tax Sensitivity}

The net redemption gains argument is also promoted as a disadvantage of open-end funds relative to its closed-end counterparts (Jeffrey and Arnott (1993)). Closed-end funds, the

15 Vanguard's Index 500 does not currently attempt to pay exiting shareholders through the existence of a cash reserve. We do not have, however, any data on the cash component of the Index 500 portfolio at all points in time. Even so, the discussion of post-tax performance in our funds which do not use cash reserves to meet net redemptions is meant as a general comment and not specifically aimed at explaining differences between our results and Vanguard's actual experience. 
argument states, never experience ebbs of money and, therefore, sell portions of their portfolios only in response either to changes in the index weights resulting from increases or decreases in shares outstanding or to changes in the index's constituents. This argument ignores the fact that while closed-end funds do not have ebbs, flows of new money are also limited. The net sales of open-end equity funds in general and Vanguard's Index 500 in particular dwarf the amount of money received by both open-end and closed-end funds each month through securities' distributions such as dividend payments. The ability to invest large amounts of "new" money from net sales in an open-end fund provides substantially more slices of securities which, on average, have a higher basis than the securities in a closed-end fund if share prices rise over time. When securities must be sold, therefore, the open-end fund will most likely realize a lower percentage of capital gains relative to basis value than its closed-end counterpart.

Our claim that open-end funds outperform their closed-end equivalents for taxable investors is borne out in Table 3. Our closed-end SURGE funds yield the same (or even slightly better) pre-tax performance yet lose more of their return to taxes. On average, the closed end funds lose 20-40 basis points per year relative to our open-end funds for mid-tax and high-tax investors. One interesting result is that our strategy of booking losses makes a much larger difference in the post-tax returns for our closed-end funds than for the open-end funds. Our strategy of realizing large capital loss positions increases post-tax retums by as much as 27 basis points per year over the HIFO only closed-end fund.

The finding that booking losses is more beneficial in closed-end funds is consistent with our argument that closed-end funds are more tax disadvantaged. First, since there are no ebbs in a closed-end fund, potential loss positions remain unrealized since HIFO procedures are less 
likely to be implemented. Second, as security prices rise over time, the lack of new money flowing into the funds to provide additional, and, on average, higher bases, ensures that HIFO procedures, when implemented, will result in more realized capital gains for the closed-end fund than in equivalent open-end variants. By realizing losses with a simple trading strategy, we are better able to realize loss positions in the closed-end funds to offset future capital gains.

Tables 2 and 3 also report the average turnover rates for each strategy. While still extremely low by industry standards ${ }^{16}$, the strategy of booking losses does increase portfolio turnover rates relative to a less aggressive trading strategy. For our open-end SURGE funds, for example, average turnover increased from 10.99 percent of average assets per year for the "HIFO only" strategy to 17.57 percent per year for the "HIFO, $75 \%$ " strategy over the ten-year period 1982-1991. Even though turnover increases with our 5-50-75 trading rule, the improvement of up to 95 basis points per year on the return for taxable investors would not be offset by the extra costs associated with the incremental rise in turnover rates.

As previously mentioned, Vanguard's Index 500 engages in higher frequency trading than our SURGE funds since we did not have access to Vanguard's daily cash flow history. Higher frequency trading most likely accounts for the differences in turnover rates between our "HIFO only" fund and Vanguard's Index 500 Fund. Implicitly, of course, our pre-tax returns reflect this discrepancy since we subtracted Vanguard's actual expense ratio (which is based on their turnover experience) from our annual returns calculations. On a post-tax basis, daily trading activity on Vanguard's part may result in additional differences with our SURGE funds. Positive assets.

${ }^{16}$ The average annual turnover rate for equity mutual funds is about 100 percent of average 
net sales within a given month, which would result in a purchase of securities for our SURGE funds, might have been generated by many large daily net sales and a few daily net redemptions. The sale of securities to meet a daily net redemption could result in more capital gains realizations. This is especially true for Vanguard's Index 500 since it does not use a HIFO identification strategy. We believe that higher frequency trading helps explain a portion of Vanguard's larger capital gains realizations; however, because of HIFO accounting, we do not believe that applying our SURGE strategies to daily portfolio management would force us into realizing any additional net capital gains.

\section{Annual Statistics for Open-End and Closed-End Variants}

Tables 4 and 5 present annual summary statistics for our open-end and closed-end SURGE funds, respectively. These tables report the year-end NAV along with annual pre-tax total returns, dividend payments per share, long-term capital gains distributions per share, tumover rates, and year-end total assets (in millions). In addition, we report the end-of-year value of capital loss carryovers, unrealized capital losses, and unrealized capital gains as percentages of year-end assets. Table 6 reports NAV, pre-tax return, dividends, long-term capital gains, and turnover rates for the Vanguard Index 500 as taken from Momingstar ${ }^{17}$.

Comparing Tables 4 and 6 shows how our open-end, HIFO only strategy improves on Vanguard's experience. The Vanguard Index 500 has distributed long-term capital gains every

17 The NAV numbers are not directly comparable between our funds and Vánguard's Index 500 since our funds began with different NAVs. 
year since 1979. Our "HIFO only" SURGE fund does not make a capital gains distribution until 1984. Over the fifteen year period from 1977-1991, the "HIFO only" SURGE fund makes capital gains distributions in only four of those years. By deferring the realization of capital gains into the future, our HIFO only fund allows its shareholders to earn more of its return through increases in NAV (unrealized capital gains) than in realized gains distributions.

Table 4 also shows that when we combine a HIFO strategy with our 5-50-75 trading rule, all realized capital gains distributions are eliminated for the entire 1977-1991 period. The market crash of 1987 was especially beneficial for our desire to realize capital losses as we ended the year with a loss carryover of nearly eleven percent (approximately 84 million dollars) of our total assets. Another interesting fact is that even though our total returns were 16.03 percent in 1988 and 31.21 percent in 1989, our loss carryovers from 1987 easily offset all realized capital gains. Our HIFO only fund, however, was not able to offset gains in 1989 and had to make a 33 cent per share capital gains distribution.

We have been able to eliminate all realized capital gains distributions since 1976 for our constructed open-end, "HIFO, 75\%" fund. Can this strategy be maintained for even longer periods? We believe that it can. In fact, we believe that our "HIFO, $75 \%$ " fund is in even better shape than our "HIFO only" fund to continue its considerable benefits for taxable investors. At the end of 1991, the "HIFO, $75 \%$ " fund had 5.28 percent of total assets as capital loss carryforwards while unrealized capital gains represented 30.49 percent of its assets. While the unrealized capital gains component may seem high, this percentage has been fluctuating between twenty and thirty-six percent for the previous twelve years. It is hard to imagine that 
this fund would be forced to make a realized capital gain distribution in the near future ${ }^{18}$. Our "HIFO only" SURGE fund is also in good shape to maintain high post-tax returns to its investors, but it had just 0.83 percent in loss carryovers and, historically, has had trouble offsetting gains when its portfolio contained more than thirty percent of unrealized gains. The year-end unrealized gain component for 1991 was 27.93 percent.

Tables 4 and 5 clearly show the differences between closed-end and open-end funds discussed earlier. The closed-end, "HIFO only" fund makes realized gains distributions in every year since 1980. While our booking losses strategy greatly improves the closed-end performance, the strategy of realizing losses is not able to eliminate all gains distributions. In each year, the unrealized gain component is much higher for the closed-end fund than for its open-end variant, a fact which demonstrates the difficulty in reducing taxable distributions to shareholders in closed-end funds. For our closed-end funds at the end of 1991, unrealized capital gains were 59.75 percent of total assets for the "HIFO only" variant and 63.50 percent for the "HIFO, $75 \%$ " strategy. The corresponding open-end percentages were 27.93 and 30.49 , respectively.

is Volatility within the index's constituents can be helpful for the "HIFO, $75 \%$ " fund. Since the end of our analysis, for example, two major S\&P 500 constituents, IBM in 1992 and Apple Computer in 1993, have experienced share prices which have more than halved in a relatively short period of time. These sharp declines would result in large capital losses being realized by our "HIFO, 75\%" fund since 1991. 


\section{Conclusions and Extensions}

We have shown that simple tax management strategies could have improved after-tax performance of equity index mutual funds without harming before-tax retums for the 1977-1991 period. Our closed-end and open-end SURGE funds would make every investor at least as well off as the equivalent fully replicated index funds while those investors subject to taxation of dividend and realized capital gains distributions would unambiguously benefit. The additional expenses associated with the slightly higher turnover that result from these tax advantaged approaches would be small relative to the increases generated in post-tax returns. We even find that most of the tax benefits could be obtained solely through implementing HIFO accounting procedures in the sale of securities. This "HIFO only" fund always maintains the true index weights.

The strategies used to reduce or eliminate realized capital gains are shown to be more effective for open-end funds than for closed-end investment companies. The main reason for this result is, as security prices rise over time, the lack of substantial sales of new fund shares in closed-end funds implies, on average, portfolios of closed-end funds will have lower bases than their open-end equivalents. When HIFO procedures are implemented, therefore, open-end funds will tend to realize fewer capital gains than closed-end funds. In addition, the higher bases of the open-end funds implies that when strategies are used to book large capital losses, open-end funds are more likely to have significant bundles of securities which can be sold at or below the loss realization trigger. 
This paper shows that tax management policies could be effective using only the underlying securities in a fund which tracks the S\&P 500. This is a very restrictive approach. First, actively managed funds which are not tied to any specific equity index should find it easier to sell loss positions and avoid tracking problems due to wash sale restrictions since security substitutes are not restricted to a specific set of stocks. Second, there are many opportunities to use derivative securities to achieve realized capital gains reductions. The use of derivatives and straddle positions to offset realized capital gains has been discussed, for example, by Stiglitz (1983) and Constantinides and Scholes (1982).

There are many other types of mutual funds which could be created as SURGE funds. Consider a fund which invests in a well-diversified portfolio of non-dividend (or possibly very low dividend) paying securities and also implements SURGE techniques. Such a fund would never need to make any distributions to shareholders, and, therefore, all investments could grow at the pre-tax return. This fund could provide a lower cost alternative to popular variable annuity investments since there is no need to achieve tax-deferred status by wrapping the fund in an insurance policy which requires expense and mortality fee payments. Furthermore, unlike variable annuity products, there would be no penalty for withdrawing money before age 59 1/2. Finally, when money is withdrawn from the non-dividend SURGE fund, redemptions (above cost basis) would be taxed at the historically lower capital gains tax rate rather than at the income tax rate in the case of the annuity. The creation of a non-dividend SURGE fund is a subject of our ongoing research. 


\section{REFERENCES}

Constantinides, George M., 1983, Capital Market Equilibrium with Personal Tax, Econometrica 51, 611-636.

Constantinides, George M., 1984, Optimal Stock Trading with Personal Taxes: Implications for Prices and Abnormal January Returns, Joumal of Financial Economics 13, 65-89.

Constantinides, George M. and Myron S. Scholes, 1980, Optimal Liquidation of Assets in the Presence of Personal Tax, Journal of Finance 35, 439-449.

Commerce Clearing House, Inc., Capital Changes Reporter.

Dammon, Robert M., Kenneth B. Dunn, and Chester S. Spatt, 1989, A Reexamination of the Value of Tax Options, Review of Financial Studies 2, 341-372.

Dickson, Joel M. and John B. Shoven, 1993, Ranking Mutual Funds on an After-Tax Basis, NBER Working Paper No. 4393.

Huddart, Steven and V.G. Narayanan, 1993, Taxation and Institutions' Trading Decisions, Stanford University, unpublished manuscript.

Ibbotson and Associates, 1993, Stocks, Bonds, Bills, and Inflation (Ibbotson and Associates, Chicago, IL).

Jeffrey, Robert H. and Robert D. Arnott, 1993, Is Your Alpha Big Enough to Cover Its Taxes?, Journal of Portfolio Management, Spring, 15-25.

Lee, Charles M.C., Andrei Schleifer, and Richard H. Thaler, 1990, Closed-End Mutual Funds, Journal of Economic Perspectives 4, Fall, 153-164.

Stiglitz, Joseph E., 1983, Some Aspects of the Taxation of Capital Gains, Journal of Public Economics 21, 257-294. 
</ref_section> 
Table 1

S\&P 500 deletions

$(8 / 1 / 1976-12 / 31 / 1991)$

\begin{tabular}{ccc} 
Year & Deletions & Percent of Index \\
\hline 1976 & 6 & $0.38 \%$ \\
1977 & 8 & $0.30 \%$ \\
1978 & 13 & $0.33 \%$ \\
1979 & 14 & $0.85 \%$ \\
1980 & 16 & $1.14 \%$ \\
1981 & 21 & $3.12 \%$ \\
1982 & 28 & $2.31 \%$ \\
1983 & 19 & $1.86 \%$ \\
1984 & 31 & $4.33 \%$ \\
1985 & 28 & $4.98 \%$ \\
1986 & 30 & $3.34 \%$ \\
1987 & 26 & $2.62 \%$ \\
1988 & 25 & $2.67 \%$ \\
1989 & 29 & $4.24 \%$ \\
1990 & 13 & $1.09 \%$ \\
1991 & 10 & $0.68 \%$
\end{tabular}

Deletions are the total number of firms deleted from the S\&P 500 index in the calendar year. Percent of index is the sum of the percentages of the S\&P 500 that the firms accounted for at the time of deletion. 


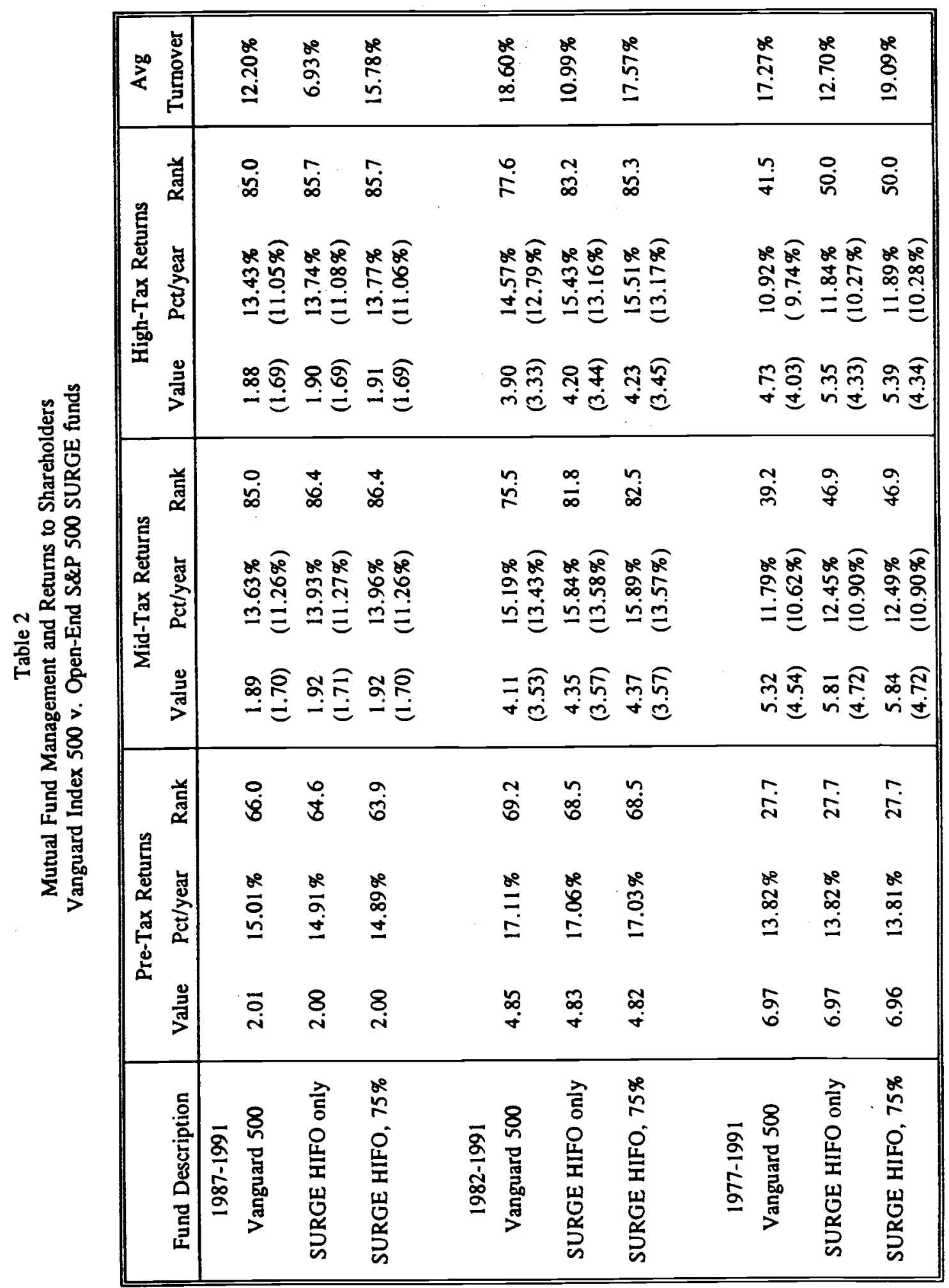




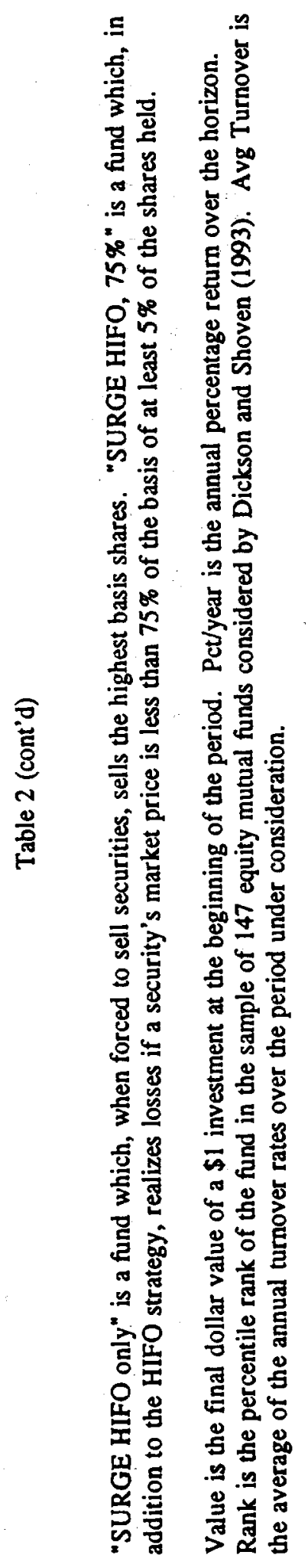




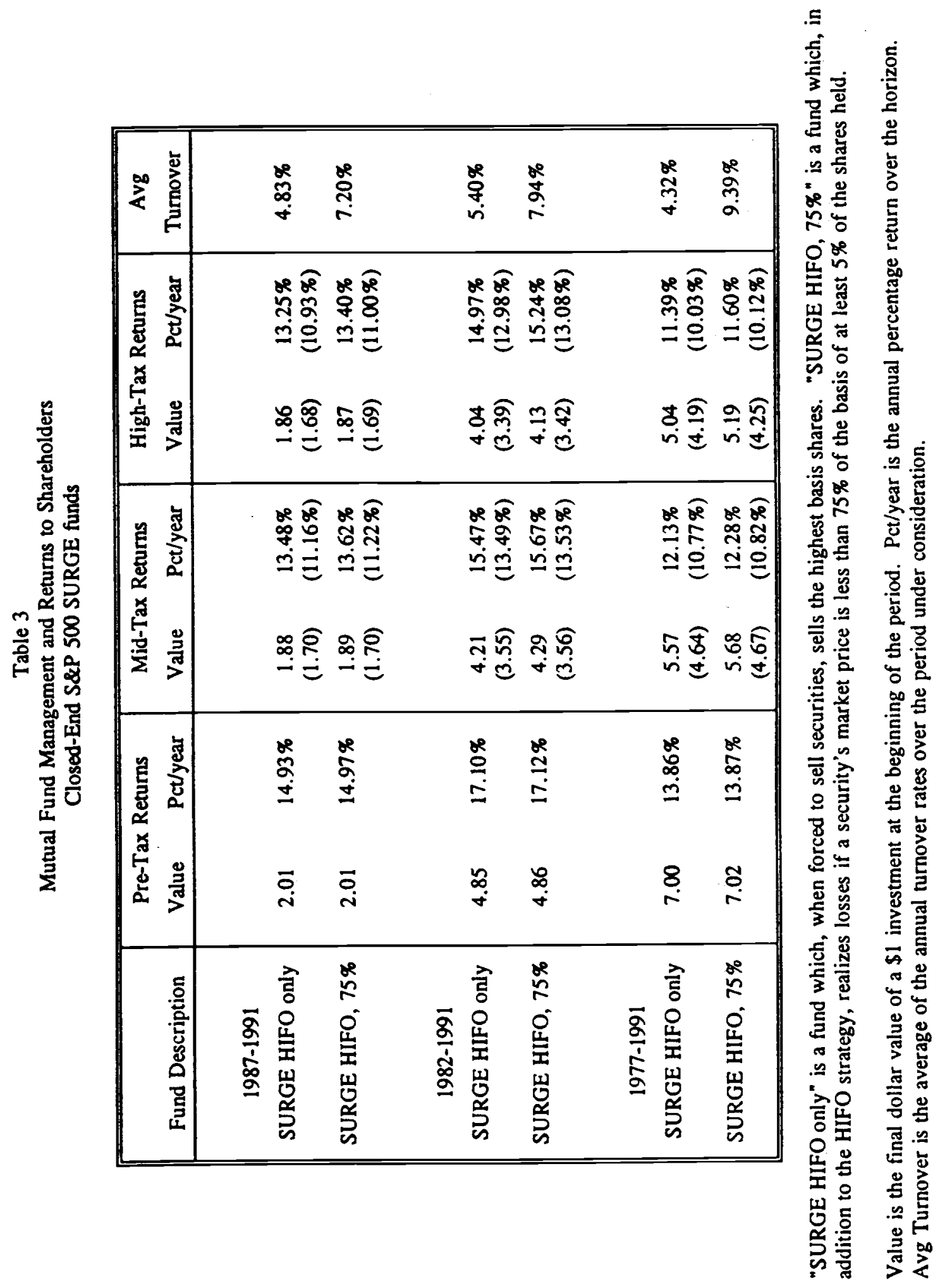


Table 4

Open-End S\&P 500 SURGE Funds

Annual Summary Statistics

Trading strategy: HIFO only

\begin{tabular}{|c|c|c|c|c|c|c|c|c|c|}
\hline \multirow{2}{*}{$\begin{array}{l}\text { Year } \\
1976\end{array}$} & \multirow{2}{*}{$\begin{array}{l}\text { NAV } \\
10.41\end{array}$} & \multirow{2}{*}{$\begin{array}{r}\begin{array}{r}\text { Pre-Tax } \\
\text { Return }\end{array} \\
4.58 \%\end{array}$} & \multirow{2}{*}{$\begin{array}{c}\text { Income } \\
0.05\end{array}$} & \multirow{2}{*}{$\begin{array}{l}\text { KG } \\
0.00\end{array}$} & \multirow{2}{*}{$\begin{array}{l}\text { T.O. } \\
(\%)\end{array}$} & \multirow{2}{*}{$\begin{array}{c}\begin{array}{c}\text { Loss } \\
\text { Carryover } \\
\text { (\% Assets) }\end{array} \\
0.02\end{array}$} & $\begin{array}{c}\text { Unre } \\
\text { Loss } \\
(\%\end{array}$ & $\begin{array}{l}\text { ized } \\
\text { Gain } \\
\text { sets) }\end{array}$ & $\begin{array}{l}\text { Assets } \\
\text { \$MM }\end{array}$ \\
\hline & & & & & & & 1.82 & 5.78 & 14.12 \\
\hline 1977 & 9.27 & $-8.06 \%$ & 0.31 & 0.00 & 4.65 & 0.42 & 8.89 & 3.26 & 21.04 \\
\hline 1978 & 9.43 & $5.96 \%$ & 0.39 & 0.00 & 8.75 & 1.42 & 7.61 & 6.02 & 30.57 \\
\hline 1979 & 10.74 & $18.15 \%$ & 0.40 & 0.00 & 32.49 & 3.68 & 4.03 & 13.49 & 39.36 \\
\hline 1980 & 13.62 & $32.04 \%$ & 0.57 & 0.00 & 22.68 & 2.75 & 2.51 & 31.04 & 50.07 \\
\hline 1981 & 12.31 & $-5.00 \%$ & 0.63 & 0.00 & 12.05 & 2.73 & 4.19 & 23.20 & 48.26 \\
\hline 1982 & 14.33 & $21.23 \%$ & 0.59 & 0.00 & 14.36 & 2.80 & 1.85 & 30.47 & 60.94 \\
\hline 1983 & 16.95 & $21.36 \%$ & 0.44 & 0.00 & 2.57 & 0.70 & 2.72 & 19.05 & 180.92 \\
\hline 1984 & 17.25 & $5.93 \%$ & 0.63 & 0.08 & 10.60 & 0.00 & 4.12 & 19.54 & 240.74 \\
\hline 1985 & 21.78 & $31.50 \%$ & 0.87 & 0.04 & 34.66 & 0.00 & 1.03 & 31.10 & 341.89 \\
\hline 1986 & 24.50 & $17.61 \%$ & 0.81 & 0.30 & 13.00 & 0.00 & 1.94 & 35.40 & 434.65 \\
\hline 1987 & 24.91 & $4.76 \%$ & 0.76 & 0.00 & 11.87 & 1.74 & 10.81 & 21.75 & 771.52 \\
\hline 1988 & 27.91 & $16.13 \%$ & 1.01 & 0.00 & 6.88 & 0.72 & 5.52 & 22.76 & 1000.57 \\
\hline 1989 & 35.30 & $31.16 \%$ & 0.97 & 0.33 & 5.59 & 0.00 & 3.26 & 29.29 & 1740.03 \\
\hline 1990 & 33.02 & $-3.41 \%$ & 1.08 & 0.00 & 9.47 & 1.70 & 7.27 & 23.98 & 2122.85 \\
\hline 1991 & 42.03 & $30.01 \%$ & 0.90 & 0.00 & 0.87 & 0.83 & 3.52 & 27.93 & 4273.50 \\
\hline
\end{tabular}

Trading strategy: HIFO and realize losses at $75 \%$ of basis

\begin{tabular}{|c|c|c|c|c|c|c|c|c|c|}
\hline \multirow[b]{2}{*}{ Year } & \multirow[b]{2}{*}{ NAV } & \multirow[b]{2}{*}{$\begin{array}{l}\text { Pre-Tax } \\
\text { Return }\end{array}$} & \multirow[b]{2}{*}{ Income } & \multirow[b]{2}{*}{$\mathrm{KG}$} & \multirow[b]{2}{*}{$\begin{array}{l}\text { T.O. } \\
\text { (\%) }\end{array}$} & \multirow{2}{*}{$\begin{array}{c}\text { Loss } \\
\text { Carryover } \\
\text { (\% Assets) }\end{array}$} & \multicolumn{2}{|c|}{ Unrealized } & \multirow[b]{2}{*}{$\begin{array}{l}\text { Assets } \\
\text { SMM }\end{array}$} \\
\hline & & & & & & & $\begin{array}{c}\text { Loss } \\
(\%\end{array}$ & $\begin{array}{l}\text { Gain } \\
\text { sets) }\end{array}$ & \\
\hline 1976 & 10.41 & $4.58 \%$ & 0.05 & 0.00 & 1.35 & 0.06 & 1.79 & 5.78 & 14.12 \\
\hline 1977 & 9.29 & $-7.82 \%$ & 0.31 & 0.00 & 16.61 & 4.76 & 4.74 & 3.63 & 21.08 \\
\hline 1978 & 9.45 & $5.90 \%$ & 0.39 & 0.00 & 17.38 & 6.54 & 3.66 & 7.26 & 30.60 \\
\hline 1979 & 10.76 & $18.13 \%$ & 0.40 & 0.00 & 35.53 & 6.36 & 2.50 & 14.68 & 39.39 \\
\hline 1980 & 13.63 & $31.90 \%$ & 0.57 & 0.00 & 25.56 & 5.10 & 1.49 & 32.32 & 50.05 \\
\hline 1981 & 12.31 & $-5.02 \%$ & 0.63 & 0.00 & 15.56 & 6.35 & 1.95 & 24.52 & 48.23 \\
\hline 1982 & 14.35 & $21.34 \%$ & 0.59 & 0.00 & 21.43 & 7.08 & 0.26 & 33.17 & 60.96 \\
\hline 1983 & 16.96 & $21.30 \%$ & 0.44 & 0.00 & 4.82 & 2.84 & 1.86 & 20.28 & 180.86 \\
\hline 1984 & 17.33 & $5.85 \%$ & 0.63 & 0.00 & 18.72 & 3.60 & 1.68 & 21.04 & 240.53 \\
\hline 1985 & 22.01 & $31.54 \%$ & 0.78 & 0.00 & 36.22 & 1.38 & 0.36 & 32.64 & 341.73 \\
\hline 1986 & 25.08 & $17.51 \%$ & 0.79 & 0.00 & 15.63 & 0.47 & 0.84 & 36.67 & 434.09 \\
\hline 1987 & 25.35 & $4.18 \%$ & 0.78 & 0.00 & 37.47 & 10.90 & 2.68 & 23.29 & 766.72 \\
\hline 1988 & 28.38 & $16.03 \%$ & 1.03 & 0.00 & 8.64 & 7.80 & 1.38 & 26.03 & 994.25 \\
\hline 1989 & 36.25 & $31.21 \%$ & 0.99 & 0.00 & 7.35 & 3.58 & 1.28 & 31.96 & 1732.39 \\
\hline 1990 & 34.05 & $-3.03 \%$ & 1.10 & 0.00 & 22.11 & 9.17 & 1.26 & 26.65 & 2124.19 \\
\hline 1991 & 43.38 & $30.12 \%$ & 0.93 & 0.00 & 3.33 & 5.28 & 0.98 & 30.49 & 4278.56 \\
\hline
\end{tabular}


Table 5

Closed-End S\&P 500 SURGE Funds Annual Summary Statistics

Trading strategy: HIFO only

\begin{tabular}{|c|c|c|c|c|c|c|c|c|c|}
\hline \multirow[b]{2}{*}{ Year } & \multirow[b]{2}{*}{ NAV } & \multirow[b]{2}{*}{$\begin{array}{c}\text { Pre-Tax } \\
\text { Return }\end{array}$} & \multirow[b]{2}{*}{ Income } & \multirow[b]{2}{*}{ KG } & \multirow[b]{2}{*}{$\begin{array}{l}\text { T.O. } \\
(\%)\end{array}$} & \multirow{2}{*}{$\begin{array}{c}\text { Loss } \\
\text { Carryover } \\
\text { (\% Assets) }\end{array}$} & \multicolumn{2}{|c|}{ Unreal ized } & \multirow[b]{2}{*}{$\begin{array}{l}\text { Assets } \\
\text { \$MM } \\
\end{array}$} \\
\hline & & & & & & & $\begin{array}{c}\text { Loss } \\
(\%\end{array}$ & $\begin{array}{l}\text { Gain } \\
\text { sets) }\end{array}$ & \\
\hline 1976 & 10.39 & $4.75 \%$ & 0.08 & 0.00 & 1.63 & 0.00 & 2.18 & 5.94 & 10.48 \\
\hline 1977 & 9.18 & $-7.84 \%$ & 0.40 & 0.00 & 0.83 & 0.01 & 12.53 & 3.91 & 9.65 \\
\hline 1978 & 9.27 & $5.94 \%$ & 0.45 & 0.00 & $1.4 ! 1$ & 0.09 & 13.65 & 6.53 & 10.23 \\
\hline 1979 & 10.42 & $17.96 \%$ & 0.51 & 0.00 & 2.20 & 0.00 & 11.16 & 15.56 & 12.06 \\
\hline 1980 & 13.16 & $31.99 \%$ & 0.55 & 0.04 & 1.94 & 0.00 & 7.68 & 30.91 & 15.92 \\
\hline 1981 & 11.79 & $-4.98 \%$ & 0.59 & 0.13 & 4.37 & 0.00 & 9.55 & 22.96 & 15.13 \\
\hline 1982 & 13.64 & $21.30 \%$ & 0.61 & 0.05 & 3.24 & 0.00 & 4.85 & 28.76 & 18.35 \\
\hline 1983 & 15.89 & $21.80 \%$ & 0.64 & 0.09 & 1.88 & 0.00 & 2.90 & 35.80 & 22.35 \\
\hline 1984 & 15.77 & $5.95 \%$ & 0.69 & 0.37 & 8.97 & 0.00 & 4.27 & 37.48 & 23.68 \\
\hline 1985 & 19.47 & $31.37 \%$ & 0.72 & 0.52 & 8.95 & 0.00 & 2.59 & 45.59 & 31.11 \\
\hline 1986 & 21.72 & $17.60 \%$ & 0.75 & 0.42 & 6.82 & 0.00 & 2.68 & 48.90 & 36.59 \\
\hline 1987 & 21.58 & $4.93 \%$ & 0.84 & 0.37 & 6.83 & 0.00 & 4.18 & 47.55 & 38.39 \\
\hline 1988 & 23.67 & $15.94 \%$ & 0.93 & 0.42 & 6.46 & 0.00 & 2.56 & 48.36 & 44.51 \\
\hline 1989 & 29.37 & $31.15 \%$ & 1.03 & 0.64 & 6.66 & 0.00 & 1.73 & 55.05 & 58.37 \\
\hline 1990 & 27.34 & $-3.33 \%$ & 0.95 & 0.10 & 2.51 & 0.00 & 4.42 & 52.41 & 56.43 \\
\hline 1991 & 34.56 & $30.02 \%$ & 0.95 & 0.03 & 1.68 & 0.00 & 2.54 & 59.75 & 73.36 \\
\hline
\end{tabular}

Trading strategy: HIFO and realize losses at $75 \%$ of basis

\begin{tabular}{rrrrrrrrrrr} 
Year & NAV & $\begin{array}{r}\text { Return } \\
\text { Re-Tax }\end{array}$ & Income & KG & $\begin{array}{c}\text { T.O. } \\
\text { (\%) }\end{array}$ & $\begin{array}{c}\text { Carryover } \\
\text { (\% Assets) }\end{array}$ & $\begin{array}{c}\text { Unrealized } \\
\text { Loss }\end{array}$ (\%ssets) & SMM \\
\hline & & & & & & & & & & \\
1976 & 10.39 & $4.75 \%$ & 0.08 & 0.00 & 1.77 & 0.05 & 2.14 & 5.94 & 10.47 \\
1977 & 9.19 & $-7.67 \%$ & 0.40 & 0.00 & 22.81 & 7.76 & 5.30 & 4.59 & 9.67 \\
1978 & 9.28 & $5.89 \%$ & 0.46 & 0.00 & 14.97 & 11.54 & 4.72 & 9.14 & 10.24 \\
1979 & 10.43 & $17.96 \%$ & 0.51 & 0.00 & 7.28 & 10.89 & 3.71 & 19.12 & 12.08 \\
1980 & 13.22 & $31.88 \%$ & 0.54 & 0.00 & 8.61 & 9.72 & 1.69 & 35.01 & 15.93 \\
1981 & 11.97 & $-4.95 \%$ & 0.59 & 0.00 & 7.85 & 10.13 & 2.04 & 27.00 & 15.14 \\
1982 & 13.91 & $21.32 \%$ & 0.61 & 0.00 & 11.06 & 10.17 & 0.21 & 35.86 & 18.37 \\
1983 & 16.29 & $21.78 \%$ & 0.65 & 0.00 & 2.33 & 7.93 & 0.37 & 42.99 & 22.37 \\
1984 & 16.56 & $5.99 \%$ & 0.70 & 0.00 & 11.06 & 5.71 & 0.58 & 43.42 & 23.71 \\
1985 & 21.03 & $31.38 \%$ & 0.73 & 0.00 & 9.92 & 1.89 & 0.26 & 50.74 & 31.15 \\
1986 & 23.92 & $17.55 \%$ & 0.78 & 0.02 & 9.01 & 0.00 & 0.53 & 53.38 & 36.61 \\
1987 & 24.05 & $4.89 \%$ & 0.87 & 0.16 & 9.73 & 0.00 & 1.32 & 52.12 & 38.40 \\
1988 & 26.33 & $15.89 \%$ & 1.03 & 0.52 & 7.58 & 0.00 & 0.77 & 52.84 & 44.51 \\
1989 & 32.70 & $31.16 \%$ & 1.11 & 0.73 & 7.26 & 0.00 & 0.48 & 58.63 & 58.38 \\
1990 & 30.61 & $-3.16 \%$ & 1.06 & 0.00 & 8.84 & 2.07 & 0.48 & 55.96 & 56.53 \\
1991 & 38.76 & $30.09 \%$ & 1.06 & 0.00 & 2.59 & 1.70 & 0.30 & 63.50 & 73.54
\end{tabular}


Table 6

Vanguard Index 500

Annual Summary Statistics

\begin{tabular}{rrrrrrr} 
Year & NAV & $\begin{array}{c}\text { Pre-Tax } \\
\text { Return } \\
(\%)\end{array}$ & Income & KG & Turnover & $\begin{array}{r}\text { Assets } \\
\text { \$MM }\end{array}$ \\
\hline 1976 & 14.73 & N/A & 0.17 & 0.00 & 2.00 & 14.33 \\
1977 & 13.01 & -7.84 & 0.57 & 0.00 & 6.00 & 21.04 \\
1978 & 13.11 & 5.87 & 0.65 & 0.00 & 8.00 & 66.15 \\
1979 & 14.64 & 18.05 & 0.75 & 0.06 & 29.00 & 78.98 \\
1980 & 17.84 & 31.92 & 0.84 & 0.52 & 18.00 & 98.74 \\
1981 & 15.52 & -5.21 & 0.83 & 0.56 & 12.00 & 91.24 \\
1982 & 17.56 & 20.97 & 0.83 & 0.25 & 11.00 & 110.03 \\
1983 & 19.70 & 21.29 & 0.88 & 0.70 & 35.00 & 233.66 \\
1984 & 19.52 & 6.21 & 0.97 & 0.39 & 14.00 & 289.70 \\
1985 & 22.99 & 31.23 & 0.94 & 1.58 & 36.00 & 394.26 \\
1986 & 24.27 & 18.06 & 0.92 & 1.99 & 29.00 & 485.10 \\
1987 & 24.65 & 4.70 & 0.69 & 0.17 & 15.00 & 826.29 \\
1988 & 27.18 & 16.22 & 1.10 & 0.32 & 10.00 & 1055.07 \\
1989 & 33.64 & 31.36 & 1.20 & 0.75 & 8.00 & 1803.84 \\
1990 & 31.24 & -3.33 & 1.17 & 0.10 & 23.00 & 2173.00 \\
1991 & 39.32 & 30.22 & 1.15 & 0.12 & 5.00 & 4345.33
\end{tabular}

Source: Morningstar, Inc. 
Figure 1

A Pre-Tax Redundant Security

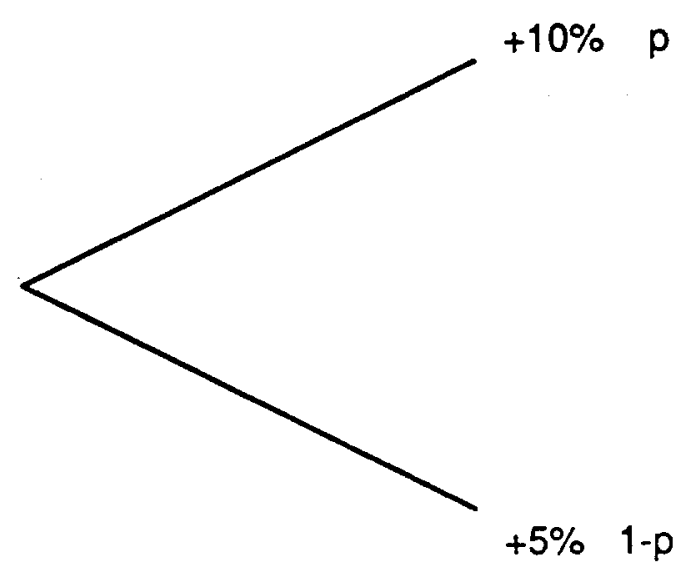

VS.
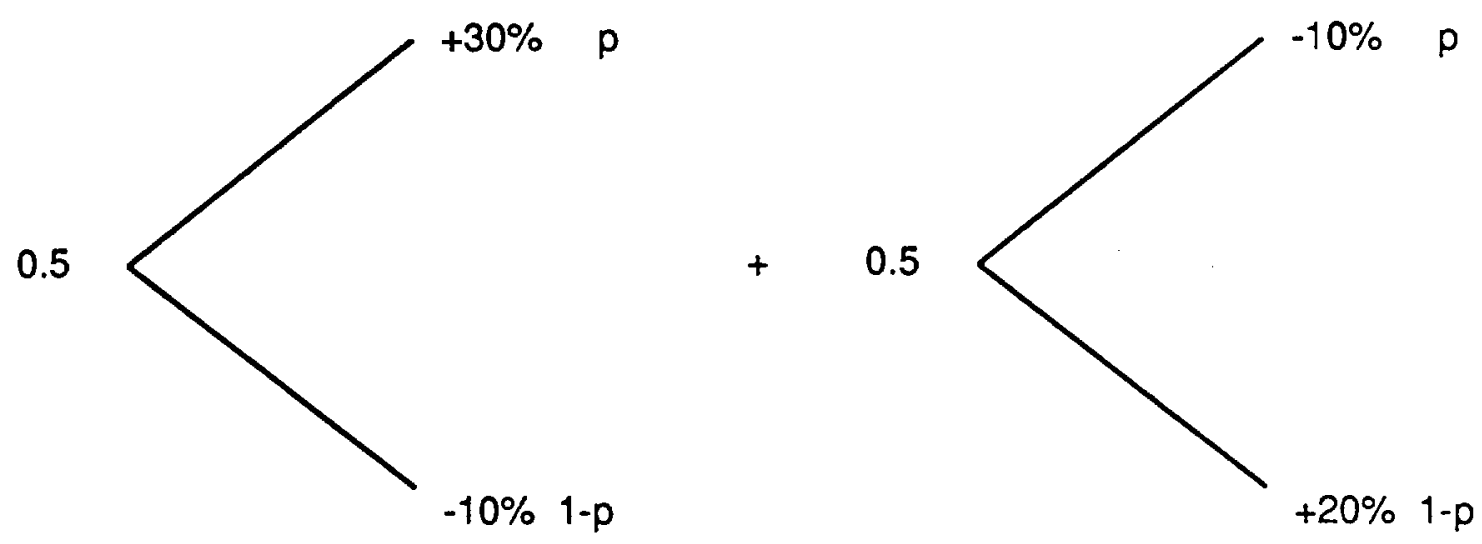

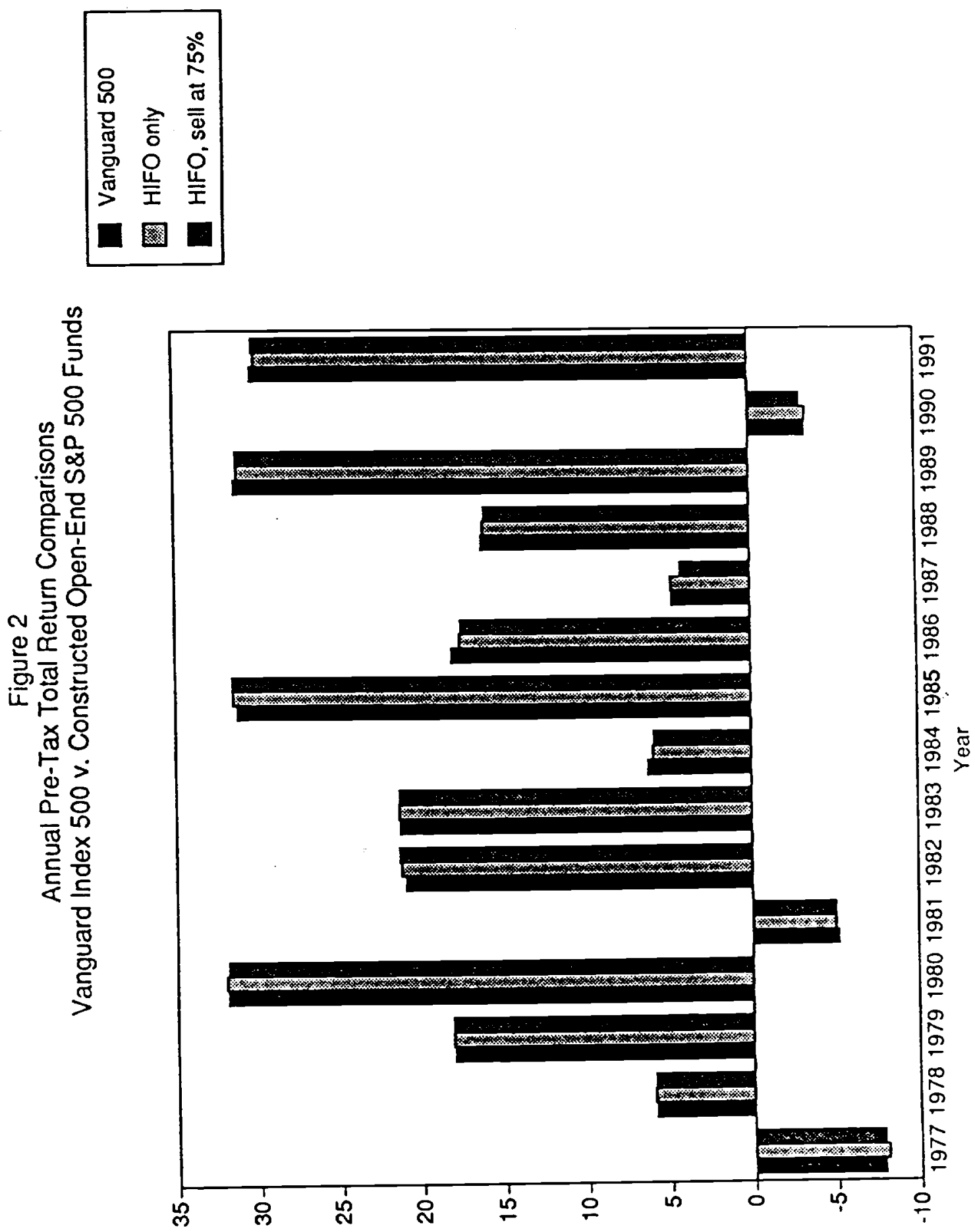

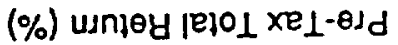

